\title{
\begin{tabular}{l|l} 
Mibraries & DSpace@MIT
\end{tabular}
}

\author{
MIT Open Access Articles
}

The CLIMODE Field Campaign Observing the Cycle of Convection and Restratification over the Gulf Stream

The MIT Faculty has made this article openly available. Please share how this access benefits you. Your story matters.

Citation: Marshall, J. et al. "The CLIMODE Field Campaign: Observing the Cycle of Convection and Restratification over the Gulf Stream." Bulletin of the American Meteorological Society 90.9 (2009): 1337-1350. ( 2009 American Meteorological Society.

As Published: http://dx.doi.org/10.1175/2009bams2706.1

Publisher: American Meteorological Society

Persistent URL: http://hdl.handle.net/1721.1/55378

Version: Final published version: final published article, as it appeared in a journal, conference proceedings, or other formally published context

Terms of Use: Article is made available in accordance with the publisher's policy and may be subject to US copyright law. Please refer to the publisher's site for terms of use. 


\section{THE CLIMODE FIELD CAMPAIGN Observing the Cycle of Convection and Restratification over the Gulf Stream}

by The Climode Group: J. Marshall, A. Andersson, N. Bates, W. Dewar, S. Doney, J. Edson, R. Ferrari, G. Forget, D. Fratantoni, M. Gregg, T. Joyce, K. Kelly, S. Lozier, R. Lumpkin, G. Maze, J. Palter, R. Samelson, K. Silverthorne, E. Skyllingstad, F. Straneo, L. Talley, L. Thomas, J. TOOle, and R. Weller

\section{A field experiment observes wintertime atmospheric and oceanic convection over the} Gulf Stream, where the ocean gives up its heat to the atmosphere during intense storms.

0 ne of the best-known hydrographic features of the midlatitude oceans is "Sub-Tropical Mode Water" (“STMW”), an upper-ocean water mass characterized by homogeneous properties and extending, in wintertime, to a depth of some $400 \mathrm{~m}$. Mode waters were first observed over $130 \mathrm{yr}$ ago by Thomson (1877). Since these pioneering observations, they have been found in all midlatitude gyres and adjacent to all major currents, including the Antarctic Circumpolar Current. As suggested by their name, mode waters are particularly voluminous [see Worthington $(1959,1976)$ and the review of Hanawa

Affiliations: Marshall, Ferrari, Forget, and Maze-Mit, Cambridge, Massachusetts; ANDERSSON-University of Hawaii at Manoa, Honolulu, Hawaii; BATES - Bermuda Institute of Ocean Sciences, St. George's, Bermuda; DeWAR-The Florida State University, Tallahassee, Florida; Doney, Fratantoni, Joyce, Straneo, TOOLE, AND Weller-Woods Hole Oceanographic Institution, Woods Hole, Massachusetts; Edson-University of Connecticut, Storrs, Connecticut; GREGG AND KelLY-University of Washington, Seattle, Washington; LozIeR AND PALTeR-Duke University, Durham, North Carolina; LUMPKIN-NOAA/Atlantic Oceanographic and Meteorological Laboratory, Miami, Florida; SAMELSON AND SKYLLINGSTAD-Ohio State University, Columbus, Ohio; SILVERTHORNE-MIT, Cambridge, and Woods Hole Oceanographic and Talley (2001)]. Given the widespread and pervasive nature of mode waters, it is clear they are a manifestation of very basic ocean dynamics, and yet what those dynamics are has eluded a comprehensive explanation. Moreover, they are of considerable climatic importance, being formed in a region of intense air-sea exchange where the ocean gives up heat to the atmosphere (see Fig. 1, top), triggering vigorous wintertime convection on both sides of the air-sea interface.

The cycle of mixing (by convection) and restratification at the heart of the mode water formation-

Institution, Woods Hole, Massachusetts; TALLEY-Scripps Institution of Oceanography, University of California, San Diego, La Jolla, California; Thомаs - Stanford University, Stanford, California CORRESPONDING AUTHOR: J. Marshall, 77 Massachusetts Ave., MIT, Cambridge, MA 02139

E-mail: jmarsh@mit.edu

The abstract for this article can be found in this issue, following the table of contents.

DOI:10.1175/2009BAMS2706.1

In final form 8 January 2009

(C)2009 American Meteorological Society 
dissipation cycle is clearly evident in the vertical temperature profiles (from the Argo ${ }^{1}$ array) shown in Fig. 1 (bottom left). We observe a rapid deepening of the surface mixed layer during February-April and a slower restratification over the remainder of the year. Note that the well-mixed fluid formed in winter has a temperature close to $18^{\circ} \mathrm{C}$; hence, North Atlantic STMW is also known as Eighteen Degree Water (EDW). In spite of a relatively well-developed observational history, many fundamental questions remain. For example, Speer and Tziperman (1992), following an approach pioneered by Walin (1982), inferred a formation rate from air-sea fluxes of roughly $15 \mathrm{~Sv}\left(1 \mathrm{~Sv}=10^{6} \mathrm{~m}^{3} \mathrm{~s}^{-1}\right)$ in the density class of $26-27 \mathrm{~kg} \mathrm{~m}^{-3}$. If the annual-mean "head" of EDW is in steady state, it must be dissipated at this rate. However, assuming subsurface diapycnal mixing rates of $10^{-5} \mathrm{~m}^{2} \mathrm{~s}^{-1}$, typical of measurements in the thermocline made by, for example, Ledwell et al. (1993), annual mode water dissipation rates are at most roughly 2 Sv (see Marshall 2005). Thus, it is difficult to see how the ocean could accommodate such a large formation rate assuming canonical interior mixing rates. Moreover, subsurface float observations of EDW volume changes suggest an annual ventilation rate only of order $5 \mathrm{~Sv}$ (see Kwon and Riser 2005). We see then that there is a considerable mismatch in mode water mass budgets, which belies a series of questions about how much is formed, how it is formed, and where mode waters are lost to other density classes. A prevailing opinion is that the resolution of the formation rate-dissipation mismatch will involve refining air-sea flux measurements as well as quantifying the importance of near-surface diapycnal eddy-driven heat transports (see Marshall 2005; Cerovercki and Marshall 2008), an area at the cutting edge of understanding the role of eddies in ocean circulation (see Ferrari et al. 2008).

Key aspects of the fluid dynamics associated with mode water formation and dispersion remain uncertain. The fundamental mechanism of mode water formation itself has been the subject of recent debate. The classical view (Warren 1972) holds that buoyancy-driven convection generates a weakly stratified column that subsequently restratifies by lateral advection. Thomas (2005), however, argues that winddriven Ekman processes can destabilize the water column by advecting heavy fluid over light. Such wind-driven formation rates can be enormous but are

\footnotetext{
${ }^{1}$ Argo is a global array of the order of 3,000 free-drifting profiling floats that measures the temperature and salinity of the upper $2,000 \mathrm{~m}$ of the ocean.
}

localized in space and time: their integral effect is as yet uncertain. The overturning process itself, whether induced by buoyancy loss or mechanically, occurs in a region of strong shear and must involve horizontal components of vorticity and slanted convection due to the strong thermal front of the Gulf Stream and the misalignment of the rotation vector and gravity (see the review by Marshall and Schott 1999). Mode waters also represent a considerable time-dependent forcing to the subtropical gyre in which weakly stratified waters are created each winter and injected in to the thermocline. The large-scale impact of mode waters on the dynamics of the gyre and the relative role of mean and eddy processes therein remain uncertain (see the mechanisms discussed in Dewar 1986; Dewar et al. 2005), as does the role of the Gulf Stream in modifying and redistributing heat and modulating wintertime convection (see Dong and Kelly 2004; Dong et al. 2007).

Finally, the problem is made even more interesting by the fact that North Atlantic STMW may play an important role in regulating ocean biogeochemical cycles in the subtropical gyre (see, e.g., Bates et al. 2002; Jenkins and Doney 2003; Palter et al. 2005). The STMW reservoir modulates oceanic uptake and decadal variability of atmospheric $\mathrm{CO}_{2}$. For the past $20 \mathrm{yr}$, the dissolved inorganic carbon content in North Atlantic STMW has increased twice as fast as anticipated from equilibrium with the atmosphere, whose $\mathrm{CO}_{2}$ levels are growing because of fossil fuel combustion and biomass burning. This additional $\mathrm{CO}_{2}$ increase in North Atlantic STMW may account for as much as $3 \%-10 \%$ of the current net annual global ocean uptake of anthropogenic $\mathrm{CO}_{2}$, but the mechanisms responsible have not been fully resolved (Bates et al. 2002).

The richness of the dynamical and biogeochemical issues reviewed above motivated a group of U.S. researchers to formulate the Climate Variability and Predictability (CLIVAR) Mode Water Dynamic Experiment (CLIMODE) to examine the physics and biogeochemistry of STMW by directly measuring air-sea heat exchange under the extreme atmospheric conditions characteristic of STMW formation and obtain contemporaneous in situ observations of the evolving physical and biogeochemical fields. Associated issues involved the examination of the North Atlantic heat, carbon, and nutrient budgets and the impacts of the newly formed STMW on the North Atlantic general recirculation. Here we both describe the observational and modeling elements that have been brought together in the CLIMODE program (see "The field experiment and associated theory 
and modeling") and present some preliminary observational and modeling highlights (see "Preliminary results"); we close by summarizing the challenges ahead (see "Summary and plans").

\section{THE FIELD EXPERIMENT AND ASSOCIATED THEORY AND MODELING. CLIMODE} was constructed around a $2-y r$ period of field measurements (2006 and 2007). Two winter cruises were timed to sample (year 1) the time of the greatest ocean heat loss to the atmosphere, and (year 2) the time when the $18^{\circ} \mathrm{C}$ layer outcrop (shown in Fig. 1 in March) was largest. Observations were collected at high spatial resolution over the top $500 \mathrm{~m}$ of the ocean to capture the processes associated with mode water formation in the context of the meandering Gulf Stream front. Simultaneously, we measured the evolving marine atmospheric boundary layer above and the air-sea fluxes that drive the two fluids. On longer time scales, the subsequent capping and initial injection of the mode water into the subtropical thermocline was also observed, as well as its eventual dispersal.

The CLIMODE field program involved a synergistic deployment of moorings, profiling floats, surface drifters, and shipboard studies, as shown in Fig. 2 (bottom). These are more fully explained online (www.climode.org). Five moorings were deployed within and to the south of the Gulf Stream. One was a surface mooring (white diamond in Fig. 2, bottom) for year-round surface flux measurements within the Gulf Stream and was deployed for $1 \mathrm{yr}$, recovered, and then redeployed for another 1-yr period. This surface mooring lasted the first full year-the first successful deployment of a surface mooring in the Gulf Streambut broke early in the second deployment. Two subsurface moorings (the position of one of them in shown by the star at the edge of Fig. 2 bottom) contained instruments that profiled temperature, salinity, and velocity in the upper ocean between nominal depths of 500 and $50 \mathrm{~m}$. These moorings also contained nitrate sensors and acoustic sound sources to help track floats. Sound

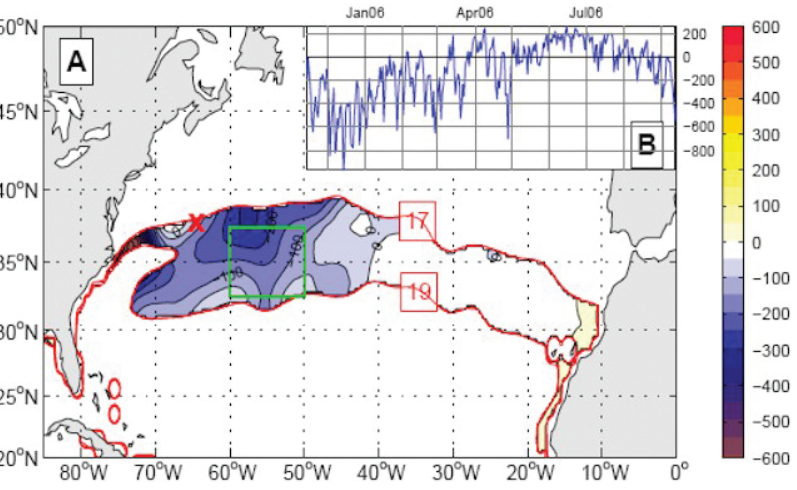

D
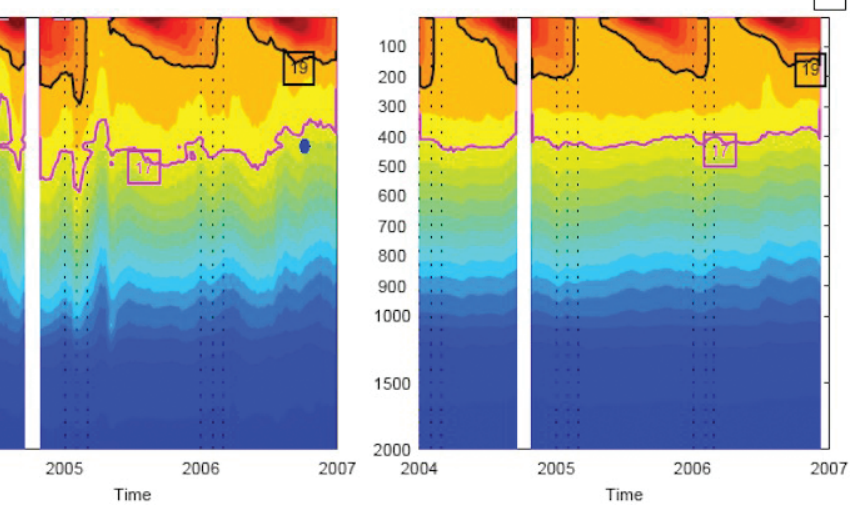

Fig. I. (a) Mean Mar net air-sea heat flux (contour interval $50 \mathrm{~W} \mathrm{~m}^{-2}$, plo mean Mar $17^{\circ}-19^{\circ} \mathrm{C}$ outcrop region (red contours). floats that occupied the box during the period are plotted in chronological order. The white stripe indicates no data. (d) The same fields as in (c), but from an ocean state estimate that uses an ocean model to dynamically interpolate all available observations.

sources were also placed on two additional moorings, providing an array for use in acoustically tracking bobber floats. The bobbers were programmed to drift on the $18.5^{\circ} \mathrm{C}$ temperature surface and periodically bob vertically between the $17^{\circ}$ and $20^{\circ} \mathrm{C}$ isotherms to measure EDW thickness and stratification. In all there were five cruises in CLIMODE. Cruises 1 and 3, made in the fall of 2005 and 2006 [on the Research Vessel (R/V) Oceanus], were primarily for servicing the mooring array. Cruises 2 and 4 were conducted in the winters of 2006 and 2007 (on the R/V Atlantis and Knorr, respectively), and were designed for intensive study of EDW formation and mixing in the region adjoining the separated Gulf Stream. During all cruises, shore-based PIs provided satellite and numerical weather prediction products for planning and interpreting shipboard observations. 


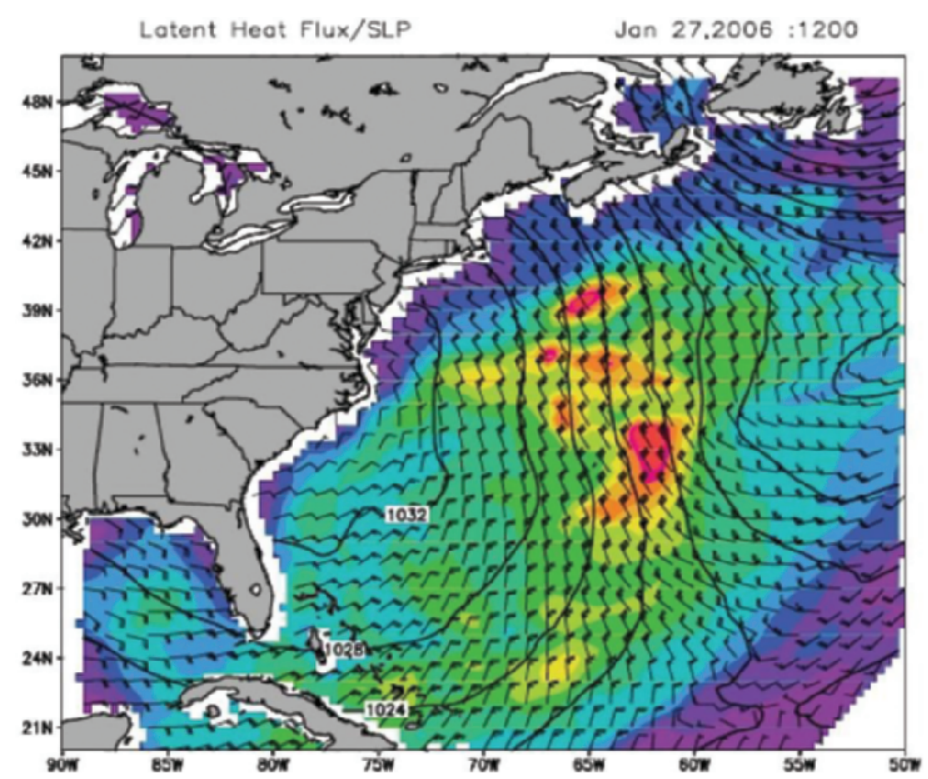

$-1000-920-840-760-660-580-500-420-320-240-160-80$

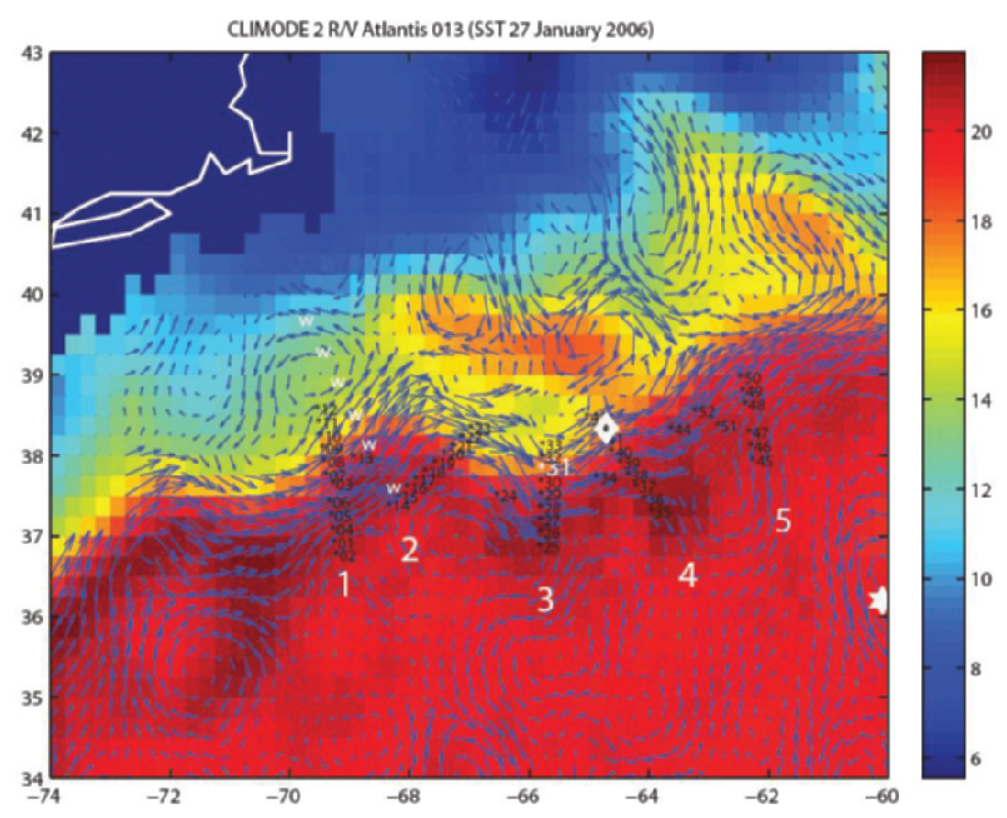

Fig. 2. (top) Surface pressure (mb), wind direction ( 1 barb $=10 \mathrm{kt}=$ $\left.5 \mathrm{~m} \mathrm{~s}^{-1}\right)$, and latent heat flux $\left(\mathrm{W} \mathrm{m}^{-2}\right)$ at 1200 GMT 27 Jan 2006. From the National Centers for Environmental Prediction. A cyclone to the north of Newfoundland, Canada, can be seen drawing cold, dry air over the Gulf Stream. All fluxes are directed out of the ocean. (bottom) Satellite microwave color SST $\left({ }^{\circ} \mathrm{C}\right.$ ) image of the Gulf Stream for 27 Jan 2006, the same time as the synoptic chart shown above. The direction of surface ocean currents from satellite altimetry are shown by the blue arrows. The black numbered sequences (labeled I-5 in white) show the position of CTD sections cutting across the Gulf Stream occupied in Jan 2006. The white symbols indicate various mooring positions: the surface buoy (white diamond) and one of two moored profilers (white star).

that crawled up and down a wire hanging from the drifting spar. The ship also supported microstructure observations to quantify mixing and deployment of radiosondes, floats and drifters. After drifting east with the GS for several days, the spar and its profiling float was recovered and a final GS section was occupied, including sampling extending toward the center of the Sargasso Sea. A variety of profiling floats and drifters deployed on the cruises, together with remote sensing, extended the observational period beyond these focused winter cruise periods.

Biogeochemcial observations were integrated into CLIMODE to

The two winter cruises (one leg on 6 January and two legs on 7 February) were designed to investigate upper-ocean mixing processes. Each cruise leg followed a similar general plan. After an initial crossGulf Stream (GS) section was occupied, a drifting spar buoy was deployed on the southern flank of the GS and tracked downstream as local ship surveys of the upper ocean and atmospheric boundary layer were carried out spanning the GS front (labeled 1-5 in Fig. 2). Ocean fine-structure observations and air-sea flux measurements were made from both the ship and the spar buoy. On the second leg of the 7 February cruise, the spar buoy was replaced by a profiling float resolve the impact of biological uptake air-sea gas exchange, advection, and mixing during STMW formation and dispersal. Water column nutrient, oxygen, dissolved inorganic carbon (DIC), and total alkalinity (TA) measurements on the winter cruises gave information on the dominant processes. Specifically, nutrient sampling was conducted on all hydrographic surveys and two nitrate sensors were mounted on the moored profilers. The hydrographic surveys produced the first cross sections of nutrients during the winter in the EDW formation region. Oxygen sensor data from profiling floats and continuous moored nitrate sensor data provided both 
high-resolution temporal records and a seasonal and gyre-scale context.

In parallel with the observational program, modeling and theoretical studies have been devised that have strong contact points with it. Process studies focused on exploring underlying mechanisms are under way, together with the use of models as tools to interpolate and integrate the observations, as shown in Fig. 2 (bottom).

PRELIMINARY RESULTS. Observations of airsea fluxes and evolution of the atmospheric boundary layer. Pulses of cold, dry air swept over the Gulf Stream region in winter drive the largest net heat loss observed anywhere over the global ocean with climatological seasonal-mean estimates approaching $400 \mathrm{~W} \mathrm{~m}^{-2}$. These cold-air outbreaks are typically associated with slow-moving low pressure systems such as that on 27 January 2006 during the first CLIMODE winter cruise, shown in Fig. 2 (top). Surface winds of $15 \mathrm{~m} \mathrm{~s}^{-1}$ (30 kt) are typical and wind events with speeds over $25 \mathrm{~m} \mathrm{~s}^{-1}(50 \mathrm{kt})$ are not uncommon. These high winds result in surface stresses that routinely exceed $1.0 \mathrm{~N} \mathrm{~m}^{-2}$ and combined latent and sensible heat fluxes from the ocean to the atmosphere that can exceed $1,000 \mathrm{~W} \mathrm{~m}^{-2}$. The strong surface forcing generates a surface wave field that averages $2.8 \mathrm{~m}$ and routinely tops $4 \mathrm{~m}$.

The measurements required to estimate airsea fluxes, and hence EDW formation rates, were gathered by three highly instrumented platforms: a moored 3-m discus buoy, a research vessel for surveys, and a drifting Air-Sea Interaction Spar (ASIS). These platforms also provided profiles of upperocean and atmospheric boundary layer structure. Additionally, numerical models and remote sensing data were used to complement the in situ measurements and provide spatial information. One of the greatest engineering challenges involved the design of a mooring that could survive in the Gulf Stream for a year-long deployment (its position is marked by the white triangle in Fig. 2).
Compounding the problems imposed by the hostile seas was the key technical challenge of keeping the buoy in place under conditions of extreme drag on the mooring line due to the $1-2 \mathrm{~m} \mathrm{~s}^{-1}$ currents of the Gulf Stream. This was accomplished by a new mooring design that was held in place by a heavy anchor with a mass of 4,200 kg. The mooring held from November 2005 until February 2007 when it finally broke free in the last of many severe storms of its 15-month deployment. An impression of the inhospitable conditions experienced on the cruise is shown in Fig. 3, where we see the mooring being recovered in the vicinity of a water spout during February 2007.

The discus buoy, ASIS, and the research vessels were all equipped with upward-looking solar and infrared radiometers; temperature, pressure, and humidity sensors; and anemometers to measure the mean meteorological variables required to estimate the fluxes from bulk formula. The mooring line of the discus buoy and the subsurface portion of ASIS were instrumented with ocean sensors to measure surface wave height and direction, pressure, temperature, conductivity (salinity), and currents. The ASIS also supported an array of wave gauges to provide directional wave measurements. It was allowed to drift within the Gulf Stream: its track for the 2006 deployment can be seen in Fig. 4, as can that of the Atlantis, carrying out GS sections while in pursuit.

The local value of the SST, combined with seasonal variability in the temperature of the air masses ad-

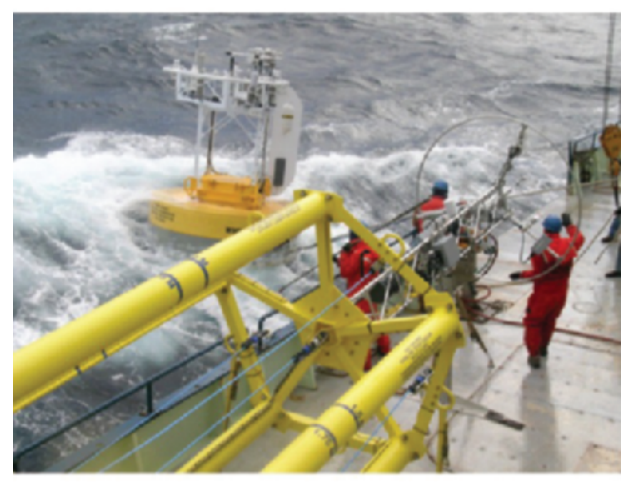

FIg. 3. (left) During the CLIMODE Knorr cruise on 9 Feb 2007, the surface meteorological buoy, which had broken loose from its mooring, was recovered near $39^{\circ} \mathrm{N}, 60^{\circ} \mathrm{W}$. In the foreground the ASIS can also be seen (photo by T. Joyce). (right) During mooring recovery we experienced periods of snow, sleet, hail, and rain, and also observed a waterspout amid the near-surface sea smoke (photo by A. Plueddemann). At this time sea surface temperatures of $19^{\circ}-20^{\circ} \mathrm{C}$ contrasted with air temperatures of $1^{\circ}-2^{\circ} \mathrm{C}$. 
vected over the region, produced a wide range of airsea temperature differences and atmospheric stability conditions during the year-long deployment. The effect of SST variability is evident in the bottom panel of Fig. 4, where on moving across the front both the direct covariance and bulk estimates of the flux from the ship-based system vary by as much as $150 \mathrm{~W} \mathrm{~m}^{-2}$. The ASIS fluxes display somewhat less variability due to the fact that the ASIS platform remained near the middle of the Gulf Stream throughout its deployment (see the track in the top panel). The ASIS ocean surface temperature slowly cooled during the deployment (red dashed line in the middle panel of Fig. 4), with additional variability driven only by synoptic
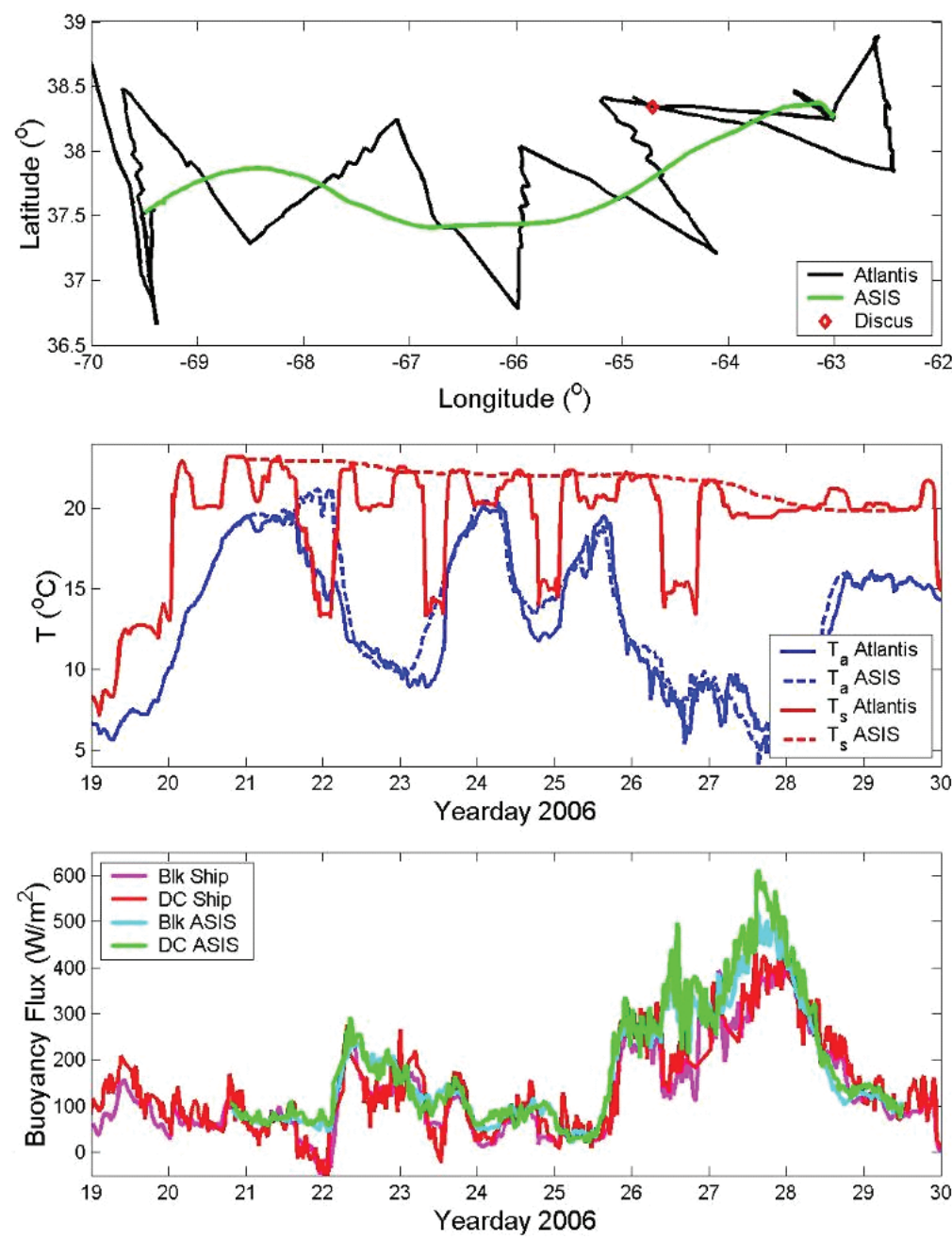

FIG. 4. (top) Relative position of the ship (Atlantis), drifting spar (ASIS), and surface mooring (discus) used to estimate surface fluxes during the 2006 field program. (middle) Time series of air temperature $T_{a}$ and near-surface ocean temperature $T_{s}$ from the ASIS and Atlantis during the transects shown in the top panel. (bottom) Direct covariance (DC) and bulk (Blk) estimates of the buoyancy flux based on $20-\mathrm{min}$ averages of the fluxes and means. Positive fluxes represent cooling. fluctuations in the air temperature (blue dashed line) and humidity. The differences between the ASIS and ship fluxes are consistent and indicate a fairly rapid adjustment of the fluxes to the large SST gradient near the Gulf Stream front. 2006 to provide temperature, humidity, and velocity profiles within and above the atmospheric boundary layer $(\mathrm{ABL})$ to investigate this response. The Earth Observing Laboratory (EOL) at the National Center for Atmospheric Research (NCAR) deployed their Integrated Sounding System (ISS) aboard the R/V Knorr in 2007. The shipboard profiles are now being combined with large-eddy simulation (LES) and surface flux measurements to examine wintertime maritime convection.

An attempt to represent the conditions encountered during February and March 2007 is shown in Fig. 5, where estimates of the total (latent plus sensible) heat fluxes are plotted against wind stress. The maximum value of the latent and sensible heat fluxes exceeded 800 and $500 \mathrm{~W} \mathrm{~m}^{-2}$, respectively, during cold-air outbreaks in March 2007, with the maximum total heat flux exceeding $1,350 \mathrm{~W}$ $\mathrm{m}^{-2}$. As described above, the largest of these heat fluxes are driven by a combination of high winds and large air-sea temperature and specific humidity differences experienced during cold-air outbreaks. Both conditions are required to achieve the largest values shown in Fig. 5. For example, the highest wind speeds reached approximately $27 \mathrm{~m} \mathrm{~s}^{-1}$ during a February storm. This drove the surface stress above $1.6 \mathrm{~N} \mathrm{~m}^{-2}$. However, the combined heat fluxes totaled "only" $750 \mathrm{~W} \mathrm{~m}^{-2}$ during this period because the air-sea temperature difference measured $4.5^{\circ} \mathrm{C}$. Although this would represent a substantial air-sea temperature difference in most regions of the ocean, this was toward the low end of the range of values measured in CLIMODE. 
It should be noted that the results shown in Fig. 5 represent bulk estimates of the flux computed from the Tropical Ocean and Global Atmosphere Coupled Ocean-Atmosphere Response Experiment (TOGA COARE) 3.0 algorithm (Fairall et al. 2003). These indirect estimates suffer from uncertainties associated with the variability of the SST in the flux footprint, variability in ABL structure, as well as uncertainties in the bulk algorithms themselves. A key objective was the direct measurement of air-sea fluxes over the region by deploying the Direct Covariance Flux System (DCFS) on all three platforms. Initial results across all platforms suggest that there is a systematic departure from the TOGA COARE algorithm at high winds: the measured transfer coefficients for the buoyancy flux are substantially lower than the TOGA COARE prediction at wind speeds above $15 \mathrm{~m} \mathrm{~s}^{-1}$.

Mesoscale upper-ocean structure, processes, and mixing. CLIMODE used several different observing strategies to study upper-ocean structure during wintertime convection: cable-lowered conductivity-temperaturedepth (CTD) to examine cross-frontal structure and ventilation; SeaSoar and shipboard Acoustic Doppler Current Profiler (ADCP) for mesoscale structure, subduction, and ventilation; Lagrangian profiling for high temporal resolution in particular locations; dispersion of surface drifters for studies of horizontal mixing at the surface; and vertical profiles of turbulence made both following a "fluid parcel" and in the cross-frontal direction.

Measurements are most easily located in "stream coordinates," defined by the location and direction of the maximum horizontal velocity over a specified depth interval. An example is shown in Fig. 6, which is an average of four sections taken on the 6 January cruise (shown in Fig. 2 bottom) in stream coordinates. Note that one can observe EDW in these sections, characterized by low stratification and high oxygen, but this was not newly formed EDW, but rather EDW that had been formed in previous years. The Atlantis 6 January cruise was early in the winter and new EDW had yet to be formed. However, the 7 January Knorr cruise occurred later in the winter and observed very deep mixed layers with newly formed EDW extending from a depth of $500 \mathrm{~m}$ right up to the surface, as shown in Fig. 7. The SeaSoar was used on the Knorr cruise in 2007. Towed through the water at a speed of $4 \mathrm{~m} \mathrm{~s}^{-1}$, it profiled between 30 and $450 \mathrm{~m}$, giving a pair of upcasts/downcasts every few kilometers. Combined with shipboard ADCP profiling to depths from 40 to $700 \mathrm{~m}$, we were able to obtain nearly an order of magnitude increase in spatial resolution over

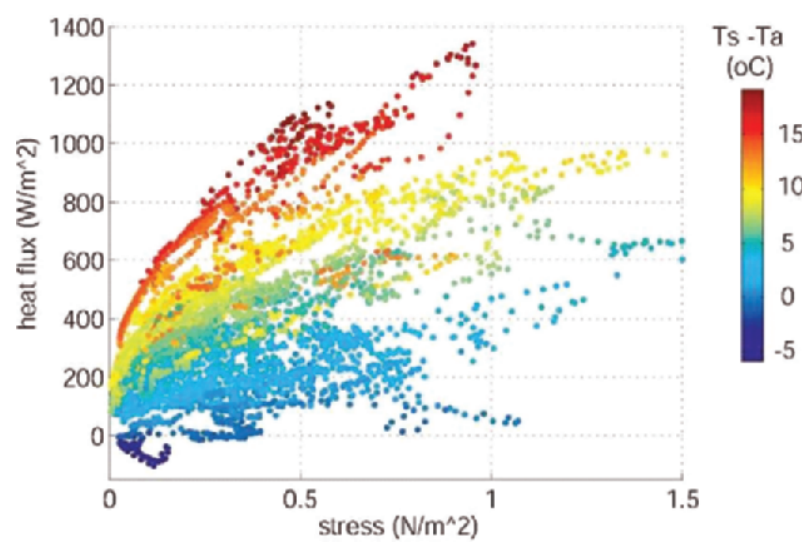

FIG. 5. Estimates of the total heat flux (sensible plus latent) versus surface stress during CLIMODE 2007 (Feb and Mar). Here positive fluxes represent heat loss from the ocean. The results are color coded as a function of sea-air temperature difference.

the cable-lowered CTDs, but with essentially the same sampling suite of instruments. These data are being examined to explore the relationship between newly ventilated water (using oxygen and fluorescence as tracers), and various other water mass properties, such as stratification and Ertel potential vorticity. In Fig. 8 we present one section from the Knorr cruise to illustrate some of our data. It was one of the first sections made on the first leg of the 2007 cruise, when the warm side of the Gulf Stream was closer to $19^{\circ} \mathrm{C}$ with a $\sigma_{\theta}$ of $26.25 \mathrm{~kg} \mathrm{~m}^{-3}$. We can see this high-oxygen, weakly stratified water at a distance of $50-60 \mathrm{~km}$ in the cross-stream coordinate, looking downstream. On the cold side of the Gulf Stream (the core being at the origin of the cross-stream distance), we again see high-oxygen and weakly stratified water, here at the surface. Over the course of the transit of these water masses through the study region, both evolve into Subtropical and Slope Mode Waters.

Evidence of subduction was also provided by electromagnetic (EM) profiling float 1636 (EM enables the float to measure fine structure) during the 2007 cruise shown in Fig. 9. It reveals a tongue or lens of anomalously low-salinity water around the depth of $200 \mathrm{~m}$ early in the leg-1 deployments. This could only have come from the north side of the Gulf Stream front. Most striking are the intense, oscillatory motions in the surface waters, which in all probability are forced by the varying wind stress. The profiling float drifts horizontally with the depthaveraged upper-ocean currents over the interval that they profile. Over this time period, float 1636 tended to drift south relative to the waters at $300-\mathrm{m}$ depth into the region with a well-developed pycnostad of 

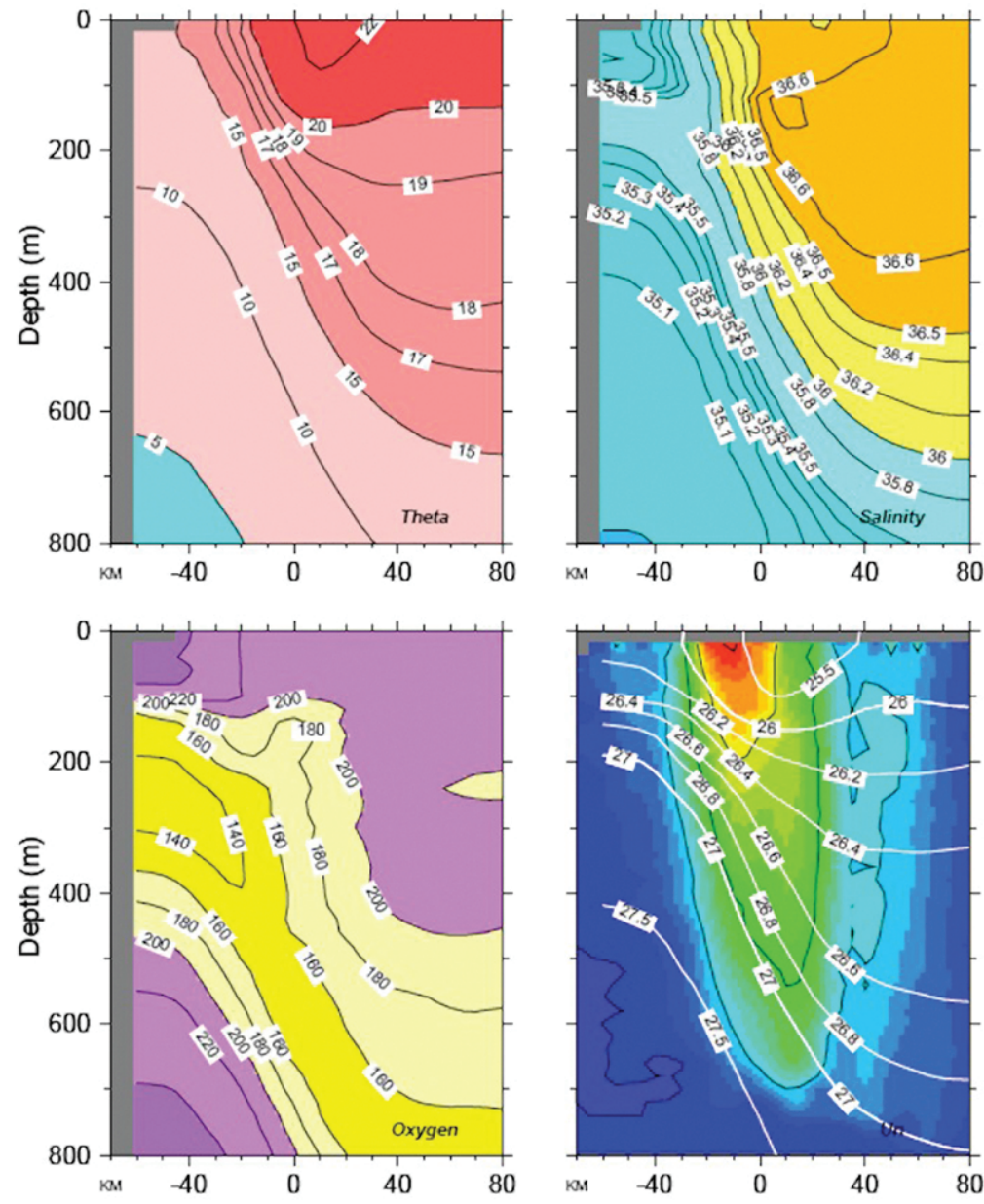

FIG. 6. The average of the four complete CTD sections (from the Atlantis cruise, labeled I-4 in Fig. 2), which spanned the Gulf Stream presented in stream coordinates. The (top left) potential temperature $\left({ }^{\circ} \mathrm{C}\right)$, (top right) salinity (psu), (bottom left) dissolved oxygen ( $\left.\mu \mathrm{mol} \mathrm{kg}^{-1}\right)$, and (bottom right) downstream velocity $\left(\mathrm{m} \mathrm{s}^{-1}\right)$, the latter with color changes at $0.1 \mathrm{~m} \mathrm{~s}^{-1}$ increments and contours at $0,0.5, I .0,1.5$, and $2.0 \mathrm{~m} \mathrm{~s}^{-1}$, are shown. Potential density contours (white lines) are also shown on this panel. The EDW is the region of low stratification and high oxygen at depths of 200-400 m, 40-80 km from the "center" of the coordinate system.

Dispersal of mode water and largescale implications. A combination of profiling floats, subsurface moorings, and shipboard hydrographic sampling was used to explore the mechanisms responsible for the dispersal of EDW within the subtropical gyre. These measurements also provide spatial and temporal context for the brief, but intensive, wintertime observations of surface buoyancy flux and mixing processes described above.

potential density around $26.3 \mathrm{~kg} \mathrm{~m}^{-3}$, which is also evident in the SeaSoar section (Fig. 8). Variations in the observed surface layer properties appear to be a mix of horizontal displacements across the Gulf Stream stratification and local changes driven by air-sea exchange and mixing. As yet unexplained is the correlation evident in Fig. 9 between surface layer meridional velocity and potential density on the effective inertial time scale ("effective" because absolute vorticity can be very different from planetary vorticity).

An important focus of CLIMODE is the characterization of lateral eddy processes in the upper ocean. Accordingly, to estimate rates of dispersion, an array of 60 satellite-tracked drifting buoys, drogued to follow currents at $15 \mathrm{~m}$, was deployed during the winter 2007 Knorr cruise, on or near the Gulf Stream front and in the recirculation gyre. Their subsequent dispersion exhibits behavior consistent with Richardson's (1926; Richardson and Stommel 1948) $4 / 3$ law at separation distances of $1.5-300 \mathrm{~km}$, and diffusion at separation distances of greater than $300-400 \mathrm{~km}$.
A total of 49 subsurface floats were deployed during four CLIMODE field expeditions to directly observe the Lagrangian evolution of temperature, salinity, oxygen, and potential vorticity of recently subducted EDW and to characterize the mesoscale processes contributing to its horizontal redistribution and vertical modification. Many of the floats exhibit particularly convoluted trajectories that highlight the eddy-rich nature of the circulation near the Gulf Stream. For example, float 2721 (Fig. 10) spent almost 18 months meandering about between $32^{\circ} \mathrm{N}$ and the Gulf Stream and recorded temperature, salinity, and oxygen profiles through two winter seasons. Temperature and oxygen profiles illustrate the formation of deep wintertime mixed layers and the subsequent springtime restratification that caps the recently ventilated EDW.

Forty acoustically tracked bobbers were deployed near the southern edge of the Gulf Stream to directly measure the time-varying velocity and stratification of the EDW layer in the northwestern subtropical gyre. The bobbers were targeted specifically at the EDW layer, and while drifting they use active buoy- 
ancy control to closely follow the $18.5^{\circ} \mathrm{C}$ temperature surface (roughly the center of the EDW thermostad). The large-scale circulation exhibited by the bobbers appears consistent with that inferred from historical hydrography: there is a generally southward interior flow in the EDW layer from the Gulf Stream to as far south as $22^{\circ} \mathrm{N}$.

In our analyses the profile data from the CLIMODE floats will be augmented by those resulting from the ongoing Argo measurement program. Figure 11 illustrates the complementary nature of these data sources, with the CLIMODE floats yielding substantially improved measurement resolution in the vicinity of the Gulf Stream and the Argo array providing improved

Fig. 7 (TOP). Profiles from a single CTD station taken on 13 Mar 2007 just south of the meandering Gulf Stream. This station had the deepest mixed layer observed on the cruise. Here newly formed EDW can be seen at the surface with a temperature between $17.5^{\circ}$ and $18^{\circ} \mathrm{C}$ down to a depth of $500 \mathrm{~m}$. (Note that, as elsewhere, the vertical scale is in $\mathrm{db}$ where $100 \mathrm{db}$ is equivalent to $100 \mathrm{~m}$.) This water is nearly saturated in dissolved oxygen, reaching values of about $95 \%$.

Fig. 8 (воттом). (top left) The track of a SeaSoar survey (dotted black line) is shown together with the track of EM float 1636 during the first 6 days of its drift (green dotted line, data along which are plotted in Fig. 9). Satellite SST on I5 Feb 2007 is also shown (cyan contours). All variables are plotted in the cross-stream direction based on data collected along the red line with the red diamond on the left. (top right) Potential temperature $\left({ }^{\circ} \mathrm{C}\right)$ and (lower right) downstream velocity $\left(\mathrm{m} \mathrm{s}^{-1}\right)$, both with solid black lines for $\sigma_{\theta}$, and (lower left) $\mathrm{O}_{2}$ $\left(\mu \mathrm{mol} \mathrm{kg}^{-1}\right)$ with the SeaSoar track overlaid.

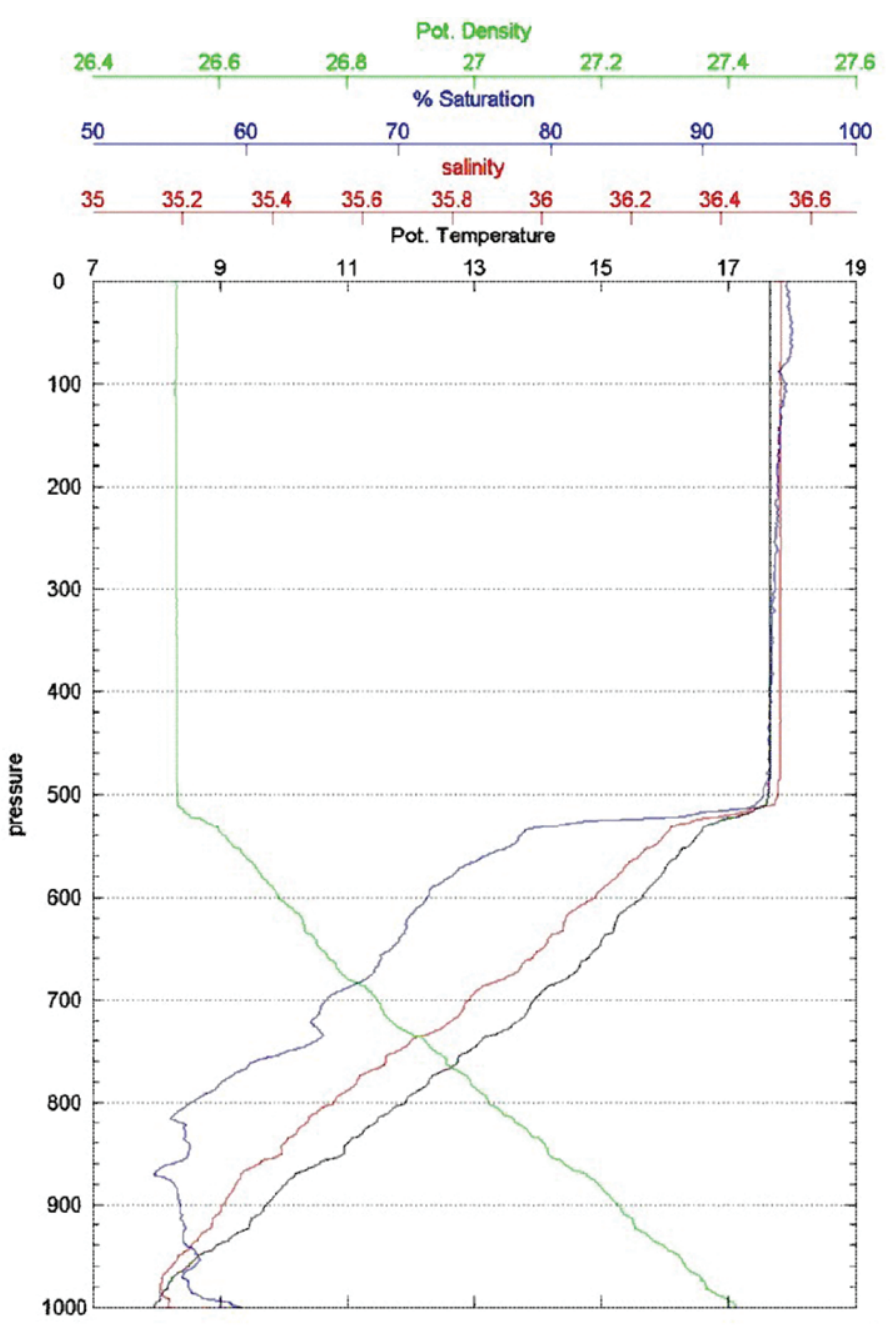

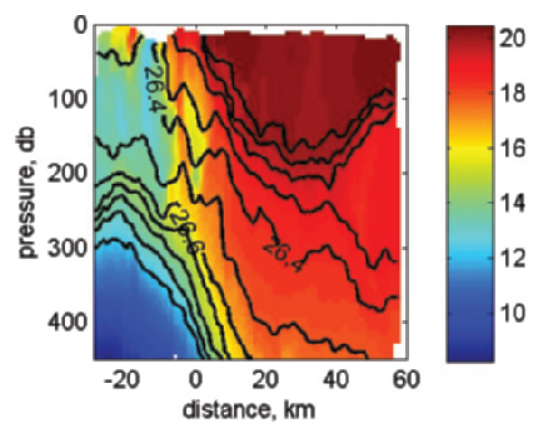
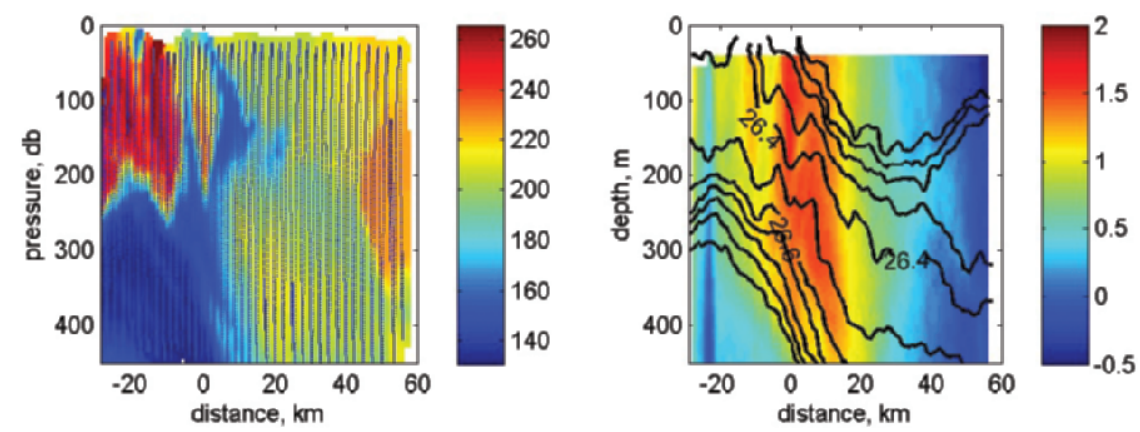
areal coverage. The combined data should allow, for example, determination of the seasonally varying volume, $V(t)$, of EDW within the subtropical gyre. The strategy we propose to pursue to draw our various data strands together is illustrated in Fig. 12, which shows results from a model data synthesis in which an ocean model [the Massachusetts Insti-
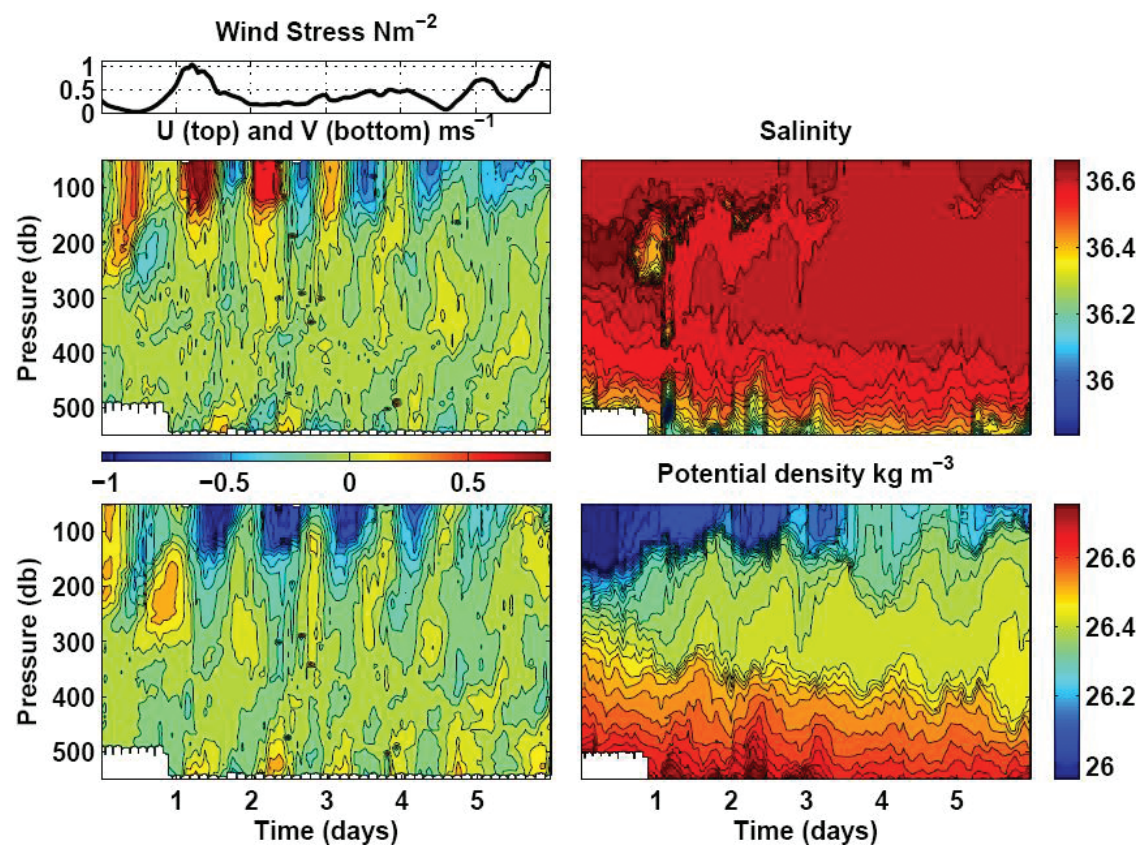

Potential density $\mathrm{kg} \mathrm{m}^{-3}$
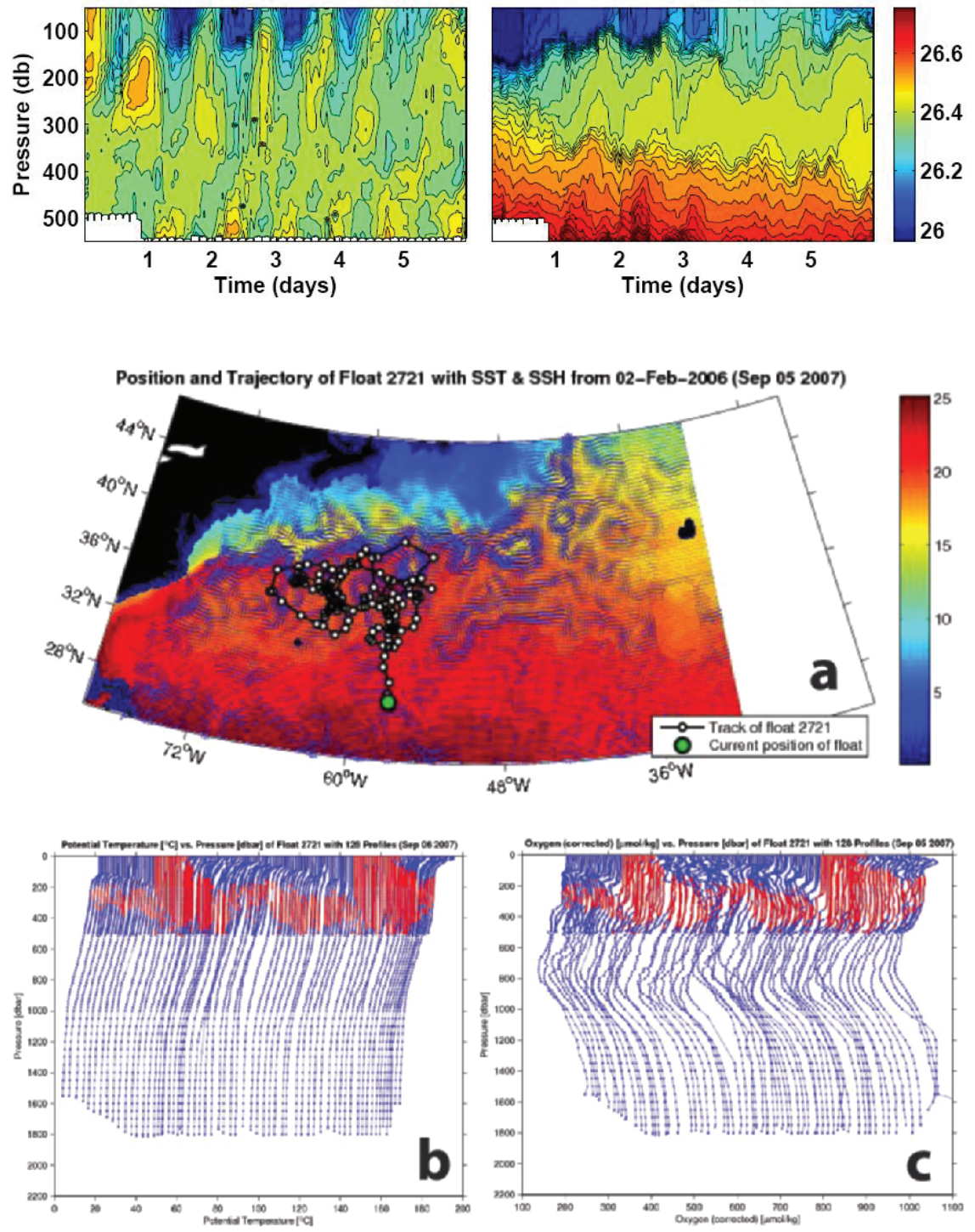

tute of Technology GCM (MITgcm) and its adjoint (Marshall et al. 1997), run at $1^{\circ}$ resolution] is used to dynamically interpolate Argo profiles, SST, and altimetric observations during the 3 -yr period of 2004-06. Air-sea fluxes and the initial temperature/ salinity $(T / S)$ fields are used as controls to minimize the misfit between the model and the observations in a least squares procedure facilitated by the adjoint (reverse) model: here, the model can be thought of as an interpolation tool. The resulting solution is very close to Argo observations [see Forget et al. (2009) and Maze et al. (2009) for a detailed discussion and the comparison between raw Argo profiles and modelinterpolated data in Fig. 1, bottom]. Wintertime formation appears to be dom-

FIG. 9 (TOP). (left) Depth-time contour plots of (top left) zonal and (bottom left) meridional relative velocity $\left(\mathrm{m} \mathrm{s}^{-1}\right)$ from the first 6 days of the deployment of EM float 1636, the track of which is shown by the green dotted line in Fig. 8. (top right) Salinity and (bottom right) potential density. The time origin is 2130 UTC $13 \mathrm{Feb} 2007$. This time period saw a moderately intense wind stress event (topmost panel on the left) that forced near-inertial currents in the surface layer, which subsequently propagated down into the stratified water column below. For display here, the depth-average velocity between 250 and $550 \mathrm{~m}$ was removed.

Fig. 10 (воттом). Trajectory and profile data from CLIMODE Argo profiling float 272I. (a) Trajectory between Feb 2006 and Sep 2007. (b) Sequential temperature and (c) dissolved oxygen profiles down to a depth of $1800 \mathrm{~m}$. Red areas indicate depths where EDW is found. 
inated by air-sea fluxes, whereas destruction is dominated by nonadvective fluxes (mixing) in the interior of the ocean. In this preliminary estimate, we find that air-sea fluxes drive $9.3 \mathrm{~Sv}$ of EDW production in the wintertime (the peak of the red curve), with a net production by air-sea heat fluxes of $4.9 \mathrm{~Sv}$ (the final value of the red curve): interior mixing in the ocean destroys $3.7 \mathrm{~Sv}$ (the final value of the black curve). Uncertainties in the curves shown in Fig. 12 are substantial: Forget et al. (2009) estimate an error of $\pm 1.8 \mathrm{~Sv}$, which is largely due to a lack of in situ measurements. As more and more of the in situ data are drawn in to our analysis (presently only a subset of the data shown in Fig. 11 are available for utilization) uncertainties in the $V(t)$ curve will be reduced, and we can use the system to study the relative importance of air-sea fluxes and interior mixing in setting the evolution of $V(t)$.

Biogeochemistry of subtropical mode water. An initial investigation of the CLIMODE nutrient data has

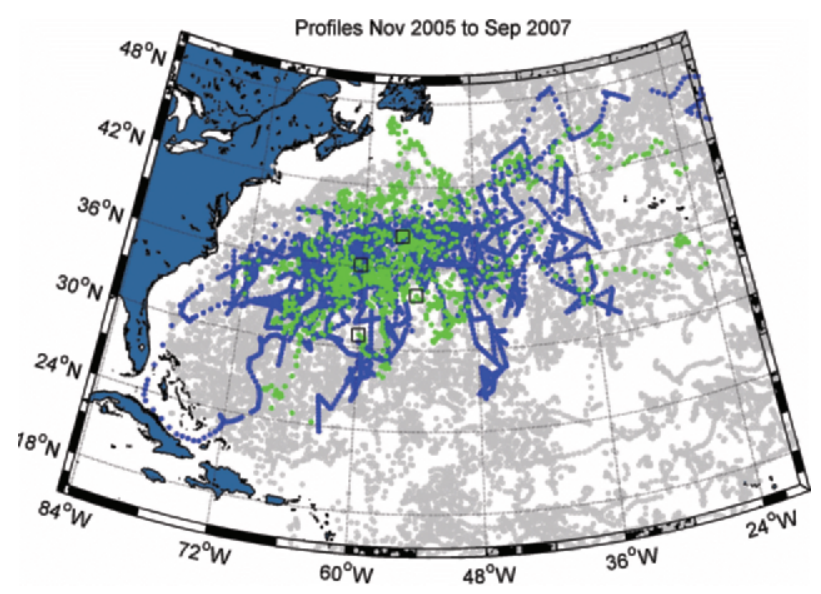

FIG. II. Spatial distribution of vertical temperature profiles derived from the Argo program (gray), CLIMODE bobbers (blue), and CLIMODE profilers (green), collected between Nov 2006 and Sep 2007.

focused on the seasonal evolution of the nutrient concentration of the surface mixed layer. Profiles of
FIG. 12. (a) A preliminary estimate of the 2004-06 mean formation rate due to air-sea fluxes $\left(\mathrm{Sv} \mathrm{m^{-2 } )}\right.$ between $17^{\circ}$ and $19^{\circ} \mathrm{C}$, as given by GCM interpolation of data (a numerical model data synthesis assimilating, as yet, only a subset of the CLIMODE data). Red shading indicates formation, blue shading destruction. Red and blue contours are Aug and Mar mean position of the $19^{\circ}$ and $17^{\circ} \mathrm{C}$ isotherms. Green contours are 2004-06 mean -0.2- and -0.6-m SSH position. In the upper left corner the surface integral of the field is given (Sv) over the total domain ( $T$ ), over positive areas $(P$, yellow and red), over negative areas $(\mathbf{N}$, blue and purple), and over the box delimited by the black dashed contour (B) [see Maze et al. (2009) for more details]. (b) Seasonal cycle of the volume of water between $19^{\circ}$ and $17^{\circ} \mathrm{C}$, and the associated Walin (1982) budget, averaged over the period 2004-06 using GCM interpolation. Errors in these estimates are considerable, of order \pm I. $8 \mathrm{~Sv}$ yr. Units are in Sverdrup years: I Sv yr = 365 $\times 86400 \times 10^{6}=$ $3.15 \times 10^{13} \mathrm{~m}^{3}$, which is the volume of water produced by a process working at a rate of I Sv for I yr [see Forget et al. (2009) for more details]. (a)

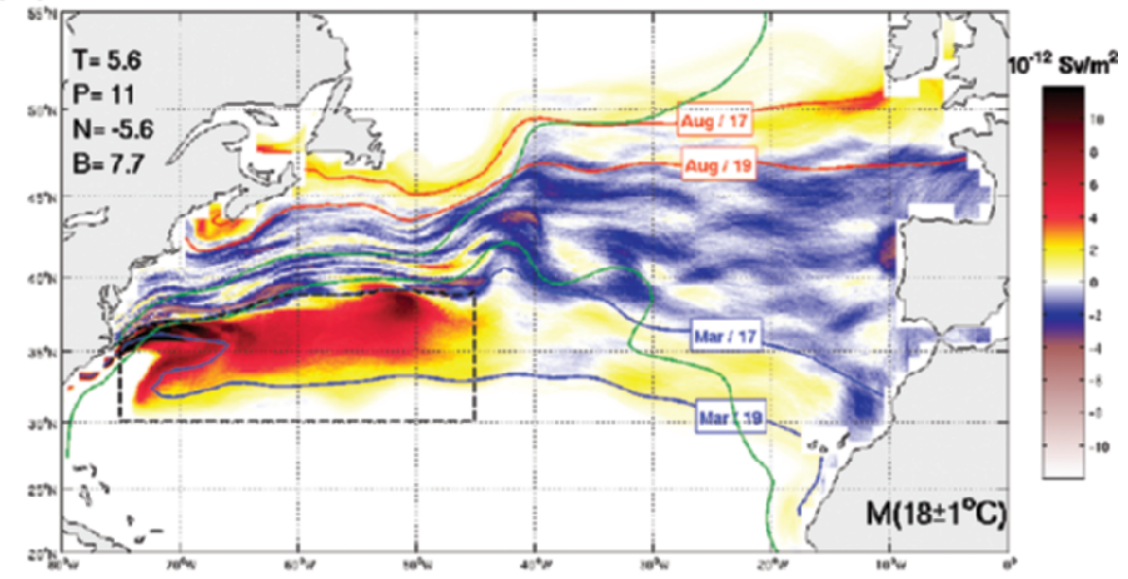

(b)

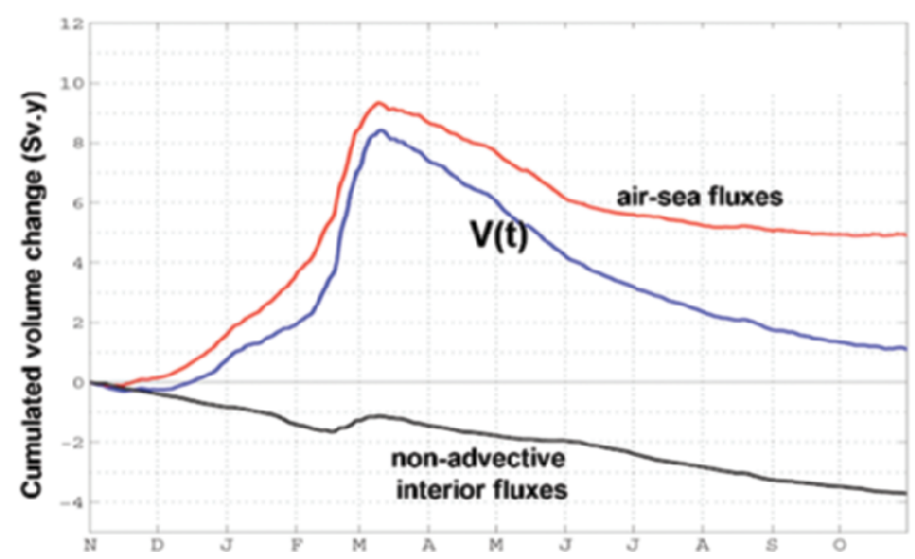


temperature and nitrate as a function of depth show the reemergence of remnant STMW over the course of a seasonal cycle (Fig. 13). Although the profiles were collected in three different years, we can use them to illustrate the annual cycle with regards to nutrients in the mode water formation region. In the summer profile, the EDW appears to lie above the deeper-than-expected nutricline and is capped by a stratified surface layer that is fully depleted in nitrate. In the fall, a shallow mixed layer of approximately $80 \mathrm{~m}$ and just over $22^{\circ} \mathrm{C}$ appears and is fully depleted in nitrate. Beneath this shallow mixed layer, vestigial EDW looks much the same as in the summer profile and depresses the nutricline. Finally, in winter, taken during the second leg of the CLIMODE 2007
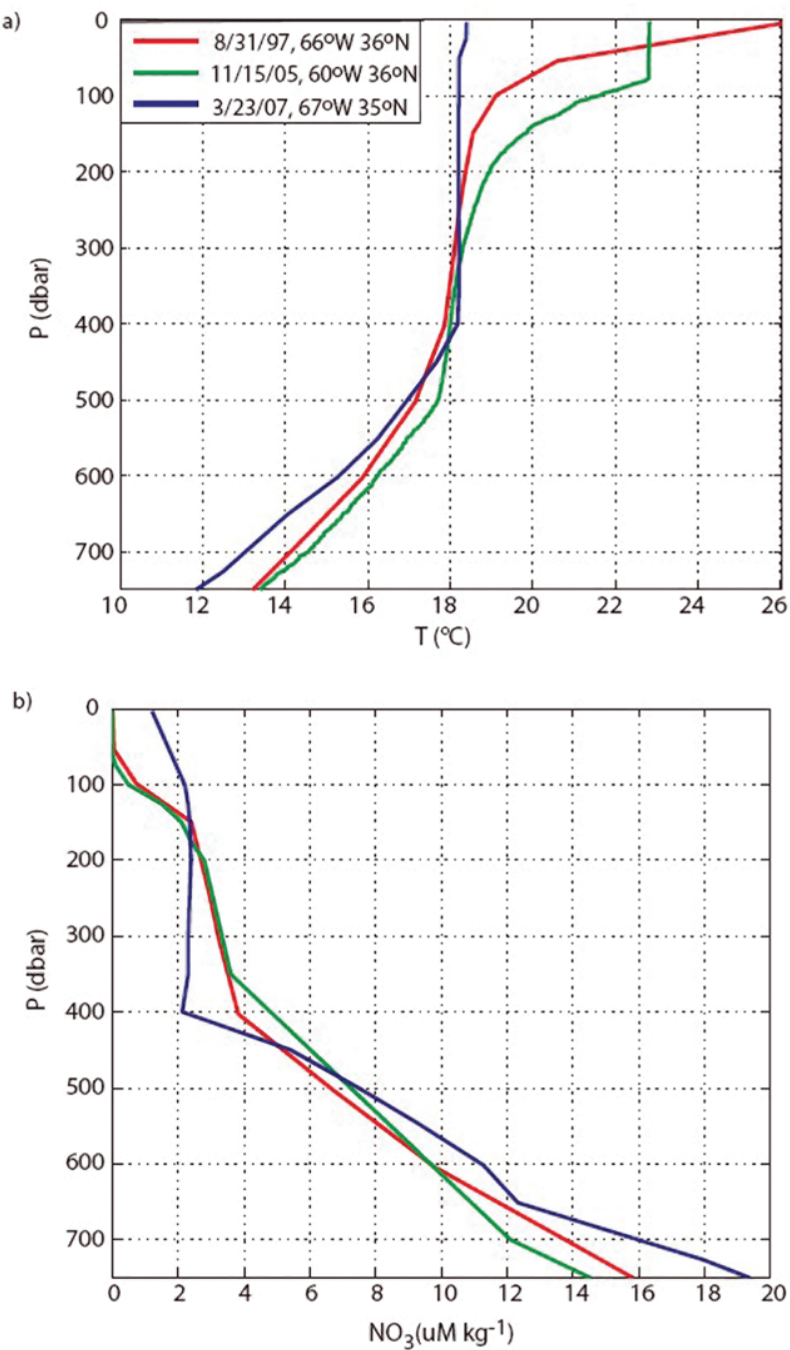

FIG. 13. Representative profiles in the EDW formation region over an annual cycle from summer (Aug 1997, red), fall (Nov 2005, green), and winter (Mar 2007, blue). (a) Temperature versus depth and (b) nitrate versus depth. cruise, the temperature profile reveals that convection (possibly coupled with more complex dynamical interactions with the front) has broken through the stratification above the EDW to produce a mixed layer of approximately $400 \mathrm{~m}$ and $18.1^{\circ} \mathrm{C}$. In the top $50 \mathrm{~m}$ of this recently formed EDW, the onset of restratification is evident (Fig. 13a), as is the beginning of nutrient utilization.

Presumably, the well-mixed water column had uniform nitrate from the surface to the base of the mixed layer during the convective event, and subsequent biological utilization within the euphotic zone drew down the nutrient content at the surface. Thus, a plausible, though simplistic, narrative of a winter-spring convective season is as follows: a surface-depleted layer overlies remnant EDW, which depresses the nutricline; a convective event entrains the EDW into the surface mixed layer along with its nutrients that were restored during an annual cycle; nutrient utilization begins in the euphotic zone within either the mixed layer or in a surface-stratified layer that forms following convective events; and the cycle of convective events continues such that mixed layer nitrate reflects a competition between the convective entrainment of nutrients from below (and/or the lateral advection of nutrients into the mixed layer) and nutrient utilization in the euphotic zone. Thus, the EDW at the time of subduction is depleted in nutrients relative to water masses outside the realm where EDW resides. Supporting this scenario, GS water at the EDW density level can have concentrations of $10-15 \mu \mathrm{M} \mathrm{kg}^{-1}$ (Pelegrí and Csanady 1991), whereas the newly formed EDW has a concentration of approximately $2 \mu \mathrm{M} \mathrm{kg}^{-1}$.

Another major biogeochemical objective is to resolve the mechanisms responsible for the additional increase in $\mathrm{CO}_{2}$ observed in the EDW aside from anthropogenic carbon uptake (Bates et al. 2002). To accomplish this, it is necessary to quantify the contribution to the EDW inorganic carbon budget owing to air-sea gas exchange, biological production and respiration, and physical mixing and advection. Anthropogenic carbon uptake can be approximated from the observed increase in atmospheric $\mathrm{CO}_{2}$, while air-sea $\mathrm{CO}_{2}$ exchange is calculated from surface seawater $\mathrm{pCO}_{2}$ and wind speeds (Fig. 14). The contribution to the inorganic carbon budget from biological processes requires an integrative approach evaluating hydrographic data sections of dissolved inorganic carbon (Fig.14), total alkalinity, nutrients, and dissolved oxygen concentrations, along with associated modeling and theory. Conservative tracers can be used to determine the contribution owing to physical mixing and advection. 
SUMMARY AND PLANS. As described in the previous sections, our field program has successfully produced a unique suite of diverse observations of the coevolution of the atmospheric and oceanic boundary layers undergoing vigorous convection in the vicinity of the separated Gulf Stream and placed that evolution in the context of the larger-scale circulation of the subtropical gyre. The focus of the seagoing wintertime component was the mode water formation process itself: much effort was devoted to quantifying the driving air-sea fluxes and studying the detailed dynamical response of the ocean through convection and baroclinic instability. However, these smallscale wintertime processes were embedded in a larger-scale circulation revealed through the deployment a variety of autonomous floats. These are being used in conjunction with models to map the fate of the convectively modified waters and the evolution of the upper ocean over the seasonal cycle. CLIMODE has also provided the necessary ocean circulation context to collect and interpret observations of the role of mode waters in the nutrient, carbon and oxygen cycles in the subtropical gyre. A complementary biogeochemical modeling program is also underway.

Ongoing foci are addressing airsea fluxes in extreme middle-latitude conditions and their representation by bulk formulas for use in models, the relative role of wind and buoyancy forcing in driving the wintertime convective process, the nature of convection occurring in a region of strong lateral and vertical shear, the physics of the restratification phase and particularly the role of the mesoscale, the resolution of the EDW formation/dissipation conundrum, and the role of subtropical mode water in the nutrient, $\mathrm{CO}_{2}$, and $\mathrm{O}_{2}$ cycle of subtropical gyre.

ACKNOWLEDGMENTS. We thank the Physical Oceanography program of NSF, and particularly its director Eric Itsweire, for support of CLIMODE. We also thank
Tom Sanford, James Girton, and John Dunlap for loan of two EM floats for the 2007 cruises and associated data acquisition and processing support.

\section{REFERENCES}

Bates, N. R., A. C. Pequignet, R. J. Johnson, and N. Gruber, 2002: A short-term sink for atmospheric $\mathrm{CO}_{2}$ in subtropical mode water of the North Atlantic Ocean. Nature, 420, 489-493.

Cerovecki, I., and J. Marshall, 2008: Eddy modulation of air-sea interaction and convection. J. Phys. Oceanogr., 38, 65-83. 
Dewar, W. K., 1986: On the potential vorticity structure of weakly ventilated isopycnals-A theory of subtropical mode water maintenance. J. Phys. Oceanogr., 16, 1204-1216.

—, R. M. Samelson, and G. K. Vallis, 2005: The ventilated pool: A model of subtropical mode water. J. Phys. Oceanogr., 35, 137-150.

Dong, S., and K. A. Kelly, 2004: The heat budget in the Gulf Stream region: The importance of heat storage and advection. J. Phys. Oceanogr., 34, 1214-1231.

— , S. L. Hautala, and K. A. Kelly, 2007: Interannual variations in upper-ocean heat content and heat transport convergence in the western North Atlantic. J. Phys. Oceanogr., 37, 2682-2697.

Fairall, C. W., E. F. Bradley, J. E. Hare, A. A. Grachev, and J. B. Edson, 2003: Bulk parameterization of airsea fluxes: Updates and verification for the COARE algorithm. J. Climate, 16, 4571-4591.

Ferrari, R., J. C. McWilliams, V. Canuto, and M. Dubovikov, 2008: Parameterization of eddy fluxes at the ocean boundaries. J. Climate, 21, 2770-2789.

Forget, G., G. Maze, M. Buckley, and J. Marshall, 2009: Observational estimates of the seasonal cycle of North Atlantic Eighteen Degree Water volume. J. Phys. Oceanogr., in press.

Hanawa, H., and L. Talley, 2001: Mode waters. Ocean Circulation and Climate, J. Siedler, J. Church, and J. Gould, Eds., Academic Press, 373-386.

Jenkins, W. J., and S. C. Doney, 2003: The subtropical nutrient spiral. Global Biogeochem. Cycles, 17, 1110, doi:10.1029/2003GB002085.

Kwon, Y.-O., and S. C. Riser, 2005: General circulation of the western subtropical North Atlantic observed using profiling floats. J. Geophys. Res., 110, C10012, doi:10.1029/2005JC002909.

Ledwell, J. R., A. J. Watson, and C. S. Law, 1993: Evidence for slow mixing across the pycnocline from an open-ocean tracer-release experiment. Nature, 364, 701-703.

Marshall, J., 2005: CLIMODE: A mode water dynamics experiment in support of CLIVAR. Clivar Exchanges, No. 3, International CLIVAR Project Office, Silver Spring, MD, 8-14.

—
Observations, models and theory. Rev. Geophys., 37, 1-64.

—, A. Adcroft, C. Hill, L. Perelman, and C. Heisey, 1997: A finite-volume, incompressible Navier-Stokes model for studies of the ocean on parallel computers. J. Geophys. Res., 102 (C3), 5753-5766.

Maze, G., G. Forget, M. Buckley, J. Marshall, and I. Cerovecki, 2009: Using transformation and formation maps to study the role of air-sea heat fluxes in North Atlantic Eighteen Degree Water formation. J. Phys. Oceanogr., in press.

Palter, J. B., M. S. Lozier, and R. T. Barber, 2005: The effect of advection on the nutrient reservoir in the North Atlantic subtropical gyre. Nature, 437, 687-692.

Pelegrí, J. L., and G. T. Csanady, 1991: Nutrient transport and mixing in the Gulf Stream. J. Geophys. Res., 96, 2577-2583.

Richardson, L. F., 1926: Atmospheric diffusion shown on a distance-neighbour graph. Proc. Roy. Soc. London, A, 110, 709-737.

- , and H. Stommel, 1948: Note on eddy diffusion in the sea. J. Meteor., 5, 238-240.

Speer, K., and E. Tziperman, 1992: Rates of water mass formation in the North Atlantic. J. Phys. Oceanogr., 22, 93-104.

Thomas, L. N., 2005: Destruction of potential vorticity by winds. J. Phys. Oceanogr., 35, 2457-2466.

Thomson, W., 1877: Voyage of the "Challenger"-The Atlantic: A Preliminary Account of the General Results of the Exploring Voyage of the H.M.S. Challenger during the Year 1873 and the Early Part of the Year 1876. Vol. 1, Harper, 391 pp.

Walin, G., 1982: On the relation between sea-surface heat flow and thermal circulation in the ocean. Tellus, 34, 187-185.

Warren, B. A., 1972: Insensitivity of subtropical mode water characteristics to meteorological fluctuations. Deep-Sea Res., 19, 1-19.

Worthington, L. V., 1959: The $18^{\circ}$ water in the Sargasso Sea. Deep-Sea Res., 5, 297-305.

- 1976: On the North Atlantic circulation. Johns Hopkins Oceanographic studies, 6, The Johns Hopkins University Press, 110 pp.

\section{TELL YOUR COLLEAGUES!}

Our new simplified application form makes joining the AMS easier than ever!

Applications are now being accepted online at www.ametsoc.org. 